\title{
INFECCIONES DEL APARATO URINARIO MOTIVADAS POR LA SONDA PERMANENTE. HISTORIA NATURAL, MECANISMOS INFECTIVOS Y ESTRATEGIAS DE PREVENCIÓN. UNA REVISIÓN DE CONJUNTO BASADA EN NUESTRA EXPERIENCIA CLÍNICA E INVESTIGACIONES.
}

Remigio Vela Navarrete, Francisco Soriano, Cármen González Enguita, Leticia Ponte, María del Carmen López, Cristina Martín Vivas, Fernando Susanibar y Jesús Gómez.

Cátedra y Servicio de Urología. Departamento de Microbiología. Fundación Jiménez Díaz Universidad Autónoma Madrid. España.

\begin{abstract}
Resumen.- El drenaje permanente, externo, del aparato urinario, mediante sondas y tubos, causa bacteriuria. Los potenciales efectos nocivos de la bacteriuria de la sonda permanente están relacionados con; tiempo de permanencia de la sonda; localización del catéter o sonda (uretra, vejiga, riñón); material que compone el catéter (látex, silicona, etc.); tipo de bacteria infectante y sus mecanismos patogénicos específicos; estado de salud del aparato urinario drenado /radiaciones previas, tumores, etc.); estado de salud del paciente portador de la sonda (diabetes, inmunodeficiencia) y motilidad del mismo; incidentes y manipulaciones de la sonda, tales como, obstrucciones, lavados o retirada de la misma. La valoración de todos los factores enumerados permite estrategias de prevención de los episodios sépticos relacionados con la sonda permanente, estra-
\end{abstract}

tegias que pueden ser individualizadas para una mayor eficiencia. A pesar de estas medidas preventivas la infección motivada por la sonda permanente puede ocasionar episodios sépticos de extremada gravedad. La bacteriuria de la sonda permanente constituye hoy en día la mayor fuente de infección nosocomial y su prevención y tratamiento, una acción sanitaria de máxima importancia. El estudio de los mecanismos implicados en la formación de biofilms, su potencial patogénico y las estrategias preventivas han supuesto un atractivo campo de investigación clínica y experimental en los últimos años. Una síntesis de los trabajos realizados por nuestro grupo es el motivo de está revisión.

Palabras clave: Infección urinaria. Sonda permanente. Profilaxis.

Summary.- Permanent drainage of the urinary tract by catheters or tubes causes bacteriuria. The potential harmful effects of the indwelling catheter's bacteriuria are related to: time since the insertion of the catheter; location of the catheter (urethra, bladder, kidney); catheter composition (latex, silicone, etc.); type of ineffective bacteria and specific pathogenic mechanisms; health status of the urinary tract being drained (prior radiation therapy, tumors, etc.); patient's health status (diabetes, immunodeficiency) and mobility; incidents and manipulations of the catheter, such as obstruction, irrigation, or retrieval. The evaluation of all mentioned factors enables strategies for prevention of septic episodes in relation with indwelling catheters, strategies that can be individualized for greater efficiency. Despite these pre- 
ventive measures, infections secondary to the indwelling catheter may cause extremely severe septic episodes. Today, the indwelling catheter bacteriuria constitutes the greater source of nosocomial infection and its prevention and treatment a health care action of the highest importance. The study of mechanisms implied in the formation of biofilms, their pathogenic potential and preventive measures have been an attractive field of clinical and experimental research over the last years. The objective of this review is to make a synthesis of the works performed by our group.

Keywords: Indwelling catheter. Urinary tract. Infection.

\section{Sonda permanente y observación clínica:}

La cuidadosa observación clínica de los pacientes portadores de sonda permanente o catéteres de drenaje, a cualquier nivel del aparato urinario, ha podido comprobar que desarrollan, cuando dejados a su evolución natural, bacteriurias de rápida instalación, que por sí solas o asociadas a otras facilidades generadas por la sonda permanente como obstrucciones, decúbitos, traumatismos, etc., pueden provocar episodios sépticos de mayor o menor gravedad y a veces de difícil control [Kass y cols. 1957 (1), Beeson, P.B. 1958 (2), Ansell, J. 1962 (3)]. Especial relevancia y atención se ha dedicado a la sonda vesical permanente por vía uretral, el recurso más común de este tipo de drenaje, [Ellick M. 1963 (4), Vela Navarrete 1969 (5), Garibaldi y cols. $1974(6)$ ], no sólo por sus consecuencias sépticas individuales sino por haberse convertido en un foco notable de infección nosocomial [Kunin 1972 (7), Lindan 1974 (8), Sedor 1999 (9), Warren, 2001 (10)]. Este procedimiento, por sí solo, constituye una referencia básica comparativa con la bacteriuria provocada por otros tipos de sondas y drenajes (nefrostomías, ureterostomías, cistostomías, catéteres ureterales exteriorizados o autoretenibles, etc) y merece un estudio independiente y detallado.

La sonda uretral permanente constituye el recurso más común de drenaje vesical y control de la diuresis en el ambiente hospitalario, junto a otro numeroso grupo de indicaciones. En la mayor parte de las ocasiones, la sonda permanece en el paciente por períodos superiores a la semana. En su evolución natural se detectan bacteriurias significativas muy rápidamente, sin que ello necesariamente se asocie a ningún tipo de síntoma irritativo local ó sistémico. Estudios realizados en los sesentas comprobaron; que cuando la orina drena libremente, en sistemas de drenaje no cerrados, la colonización bacteriana está presente al cuarto día en el $96 \%$ de los casos; que esta colonización sucede más rápidamente en las mujeres que en los varones; que habitualmente está conformada por bacteriurias mixtas; y que con gran frecuencia los contajes bacterianos superan los niveles calificados de "bacteriuria significativas" (más de 100.000 bacterias o colonias por ml) [Kunin 1972 (7), Vela Navarrete, 1976 (11)]. También se ha comprobado que simultáneamente la uretra, y especialmente el punto de contacto entre el catéter y el meato uretral, es colonizado por bacterias, habitualmente del mismo género que las que motivan la bacteriuria y frecuentemente se produce exudado uretral que mancha ropa y apósitos próximos. [Bultitude 1973 (12)]

En general, la bacteriuria de la sonda permanente es bien tolerada. A corto plazo los problemas sépticos pueden aparecer en el momento en que se retira la sonda (Vela Navarrete y Alés 1982) (13). Esta circunstancia fue calificada de fiebre de la retirada de la sonda vesical, parangonando otra observación clínica que recibió el nombre de "fiebre del tercer día" (Altmeier 1971) (14) en referencia a los catéteres venosos utilizados para perfusión postoperatoria. A más largo plazo la bacteriuria de la sonda permanente, aliada con trastornos mecánicos producidos por la misma sonda, como úlceras de decúbito y obstrucciones, puede motivar infecciones urinarias sintomáticas y episodios más graves de pielonefritis, septicemias e incluso shock endotóxico, como procesos sistémicos. A nivel vesical es frecuente observar la formación de cálculos, en muchas ocasiones moldeantes del balón de la sonda de Foley, en forma de cáscara de huevos, habitualmente compuestos de fosfato calcio, así como cistitis incrustantes, infrecuentes pero insufribles, y más rara vez, especialmente en pacientes diabéticos e inmunodeprimidos Cistopatías enfisematosas e incluso gangrena vesical. El factor mecánico coincidente provocado por la sonda tiene notable importancia en el origen de muchos de estos procesos sépticos, motivando a veces auténticas sepsis de brecha. Simultáneamente la infección uretral puede motivar supuracion, meatitis e incluso fístulas uretrales o simples decúbitos en el ángulo penoescrotal que al retirar la sonda se transforman en estenosis de mayor o menor gravedad

La población bacteriana que se identifica en los cultivos de orina practicados en los pacientes con sonda permanente, habitualmente tomando la muestra de orina directamente de la sonda, por goteo, en un recipiente estéril, es muy variada. Depende fundamentalmente de que el enfermo esté en un ambiente extra o intrahospitalario. Motivo de especial atención ha sido el reconocimiento de las bacterias en el am- 
biente hospitalario; en la Figura 1 aparece un listado de las que fueron identificadas en nuestro servicio en 1976 (11). No se han producido grandes cambios en estos últimos veinte años y la distribución porcentual sigue siendo muy similar. Es notable que se trata fundamentalmente de enterobacterias pero de potencial patógeno muy distinto y mecanismos de acción patógenica variados. Muchas de estas bacterias son genuinos representantes de la flora bacteriana nosocomial y una de ellas, el proteous índol positivo, fue específicamente empleado por nosotros como marcador para seguir el itinerario de su expansión por el hospital, provocando infecciones cruzadas de variable gravedad (Alés y Vela 1974) (15). Serratia es otra bacteria que ha sido utilizada con los mismos fines. La proporción de gram positivos y gran negativos parece mantenerse, aunque los gran positivos van ganando protagonismo en procesos sépticos graves hospitalarios

El tratamiento de la bacteriuria de la sonda permanente ha sido motivo de muy extensos y variados estudios, con objetivos distintos. Retardar la aparición de la bacteriuria ha sido una opción razonable, confirmándose que la atención de la sonda permanente por personal especializado, junto con los sistemas de drenaje cerrados, pueden conseguir este objetivo sin mayores dificultades por períodos de tres o cuatro días (Miller y cols. 1960 (16); Guillespie y cols. 1967 (17); Butler y Kunin 1968 (18); Thortón y Andriole 1970) (19). Esto mismo puede conseguirse en la actualidad mediante lavados continuos, en sistemas cerrados de drenaje, lavados que en otro momento se realizan con antisépticos urinarios diluidos apropiadamente (acido acético al $0.25 \%$, Clorhexidina, Nitrofurazona) o Antifúngicos [Meyers 1965 (20), Martin 1962 (21)]. Se han ensayado también otras estrategias para estos fines.

Mucho más difícil ha sido conseguir esterilizar la orina de los pacientes con sonda permanente. Numerosos trabajos han demostrado que el uso de antimicrobianos de amplio espectro lo que sí consigue es sustituir las bacterias infectantes por otras más resistentes e incluso provocar mutaciones bacterianas generando subtipos de especial poder patogénico (Petersdar y cols. 1957 (22), Vela Navarrete y Ales 1971) (23). En definitiva, el abuso de antimicrobianos en estas circunstancias ha sido uno de los factores fundamentales que han convertido a los pacientes con sonda permanente en un foco de infección nosocomial grave motivando regulaciones oficiales por parte de las Agencias Sanitarias correspondientes (Botto). El tratamiento inadecuado de los pacientes con sonda permanente en el ambiente hospitalario, y muy especialmente en las Unidades de Cuidados Intensivos, originó no sólo un foco activo de infección nosocomial, si no fuente de múltiples resistencias bacterianas de grave impacto hospitalario (xx).

Los drenajes hipogástricos vesicales (cistostomías) y renales (nefrostomías) también producen bacteriura. A nivel vesical las cistostomias tienen la virtud de que al soslayar la uretra eliminan todos los riesgos mecánicos y sépticos que puedan originarse en esta zona. La posición del balón en la porción alta de la vejiga elimina también el riesgo de decúbitos sobre la mucosa vesical, haciendo menos frecuentes potenciales sepsis de brecha. A largo plazo, este tipo de derivación urinaria puede provocar complicaciones similares a las motivadas por la sonda permanente transuretral, pero ha sido motivo de menores investigaciones por ser un procedimiento más especializado. Las nefrostomías, que han ido progresivamente ganando indicaciones frente a las ureterostomías, también provocan, inexcusablemente, bacteriurias que pueden tener consecuencias funestas si se obstruye la sonda ó se manipula con lavados a presión. El decúbito que motivan las nefrostomías sobre el parénquima renal facilita sepsis de brecha y procesos de extrema gravedad. A largo plazo las nefrostomias pueden motivar litiasis, también de naturaleza fósfocalcica la mayor parte de las veces, y pielitis incrustantes.

\section{Infección urinaria de la sonda permanente. Mecanismos patogénicos. Papel de las bacterias, de los biofilms y de los biomateriales}

Las bacterias implicadas en la infección urinaria de la sonda permanente, como señalado en la tabla l, en el ambiente nosocomial, son muy variadas y con mecanismos patogénicos específicos. E.Coli, el patógeno más común, es seguramente el de menos agresividad potencial a nivel local. Es de escasa penetración tisular lesionando modestamente el urotelio. Por el contrario, cuando se dan las condiciones necesarias para superar la barrera urotelial (brechas), puede provocar graves infecciones sistémicas e incluso schock endotóxico. Esta circunstancia se produce generalmente cuando existen decúbitos prolongados, retirada de la sonda sin la previsión oportuna, con el consecuente aumento de la presión intravesical, o lavados vesicales intempestivos.

Mucho más graves a nivel vesical, pueden ser las consecuencias de una infección por bacterias ureolíticas cuyo representante más común es el Proteous. Especial atención ha recibido en nuestro ambiente una bacteria gram positiva de difícil reconocimiento en los cultivos automatizados, cuya identificación taxonómica se hizo sobre muestras aportadas por nuestro hospital. Nos referimos al 
Corynebacterium Urealiticum una bacteria de crecimiento lento, multiresistente, de gran potencial ureolítico, totalmente identificada y reconocida en nuestro hospital en 1985 (24). Está bacteria escapa con frecuencia al reconocimiento habitual en los departamentos de microbiología automatizados, por su lento crecimiento, necesitando más tiempo de incubación que una noche y es, con frecuencia, considerada como contaminante. Sin embargo, es fácilmente sospechada su presencia por el clínico, por su extraordinaria capacidad de alcalinizar la orina y producir un olor amoniacal insultante. Las orinas de los pacientes infectados por esta bacteria tienen una marcada turbidez y el sedimento, centrifugado, además del olor característico, un gran contenido protéico y mucosidad. Corynebacterium Urealiticum tiene gran apetencia por invadir las mucosas y crecer y multiplicarse en este ambiente, más que en la misma orina, por lo que con máxima facilidad y rapidez puede provocar incrustaciones, tanto en la mucosa vesical como en la piélica o ureteral. Simultáneamente puede provocar incrustaciones en el catéter ureteral o en sondas de nefrostomía o vesical, y tanto en superficie como en la luz del tubo (24-27).

El mecanismo patogénico implicado en la acción del Corynebacterium Urealiticum está directamente relacionado con su capacidad para producir ureasa y desdoblar la urea generando fosfato amonico-magnésico. Tanto las incrustaciones intraparenquimatosas o submucosas como las que se producen en la sonda están compuestas por fosfato amonico magnésico. Hemos determinado él poder ureolitico de esta bacteria en comparación con otras productoras de ureasa y sólo es superado en este objetivo por algunas variedades de Stafilococo (Rojo). Como conocido, la ureasa produce grandes cantidades de amonio, alcalinizando la orina y generando cálculos de estruvita, vesicales, ureterales o renales. La ureasa irrita la mucosa vesical o piélica provocando inflamación y debilitando sus defensas hasta conseguir la penetración de las bacterias que continúan produciendo ureasa y generando calcificaciones submucosas de estruvita, que en esta ocasión se manifiestan como incrustaciones cuyo reconocimiento tanto endoscopico como radiográfico es característico. Esta es la génesis de las cistopatías y pielitis incrustantes frecuentemente descritas en la literatura. (Soriano y cols.) (24-26).

\section{BIOFILMS Y BIOMATERIALES}

La formación de finas películas bacterianas en la parte externa y en la luz de la sonda, sobre las que sucesivos depósitos bacterianos y orgánicos pueden fijarse, ha atraído la atención de los investigado- res en los últimos años, por dos motivos fundamentales; porque puede constituir un mecanismo defensivo de las bacterias para mantener su supervivencia en ambientes hóstiles; porque puede ser una estrategia bacteriana de resistencia frente a los antimicrobianos. Hay que añadir a ello que la formación de biofilms es uno de los mecanismos de rápido deterioro de los catéteres y sondas permanentes, provocando su obstrucción, ocasional, con consecuencias patogénicas de notable gravedad (28-30).

La formación de los biofilms no difiere en su mecanismo íntimo de la producción de incrustaciones submucosas; ciertamente, ambos procesos pueden darse simultáneamente y proteínas y bacterias constituir los mismos elementos patogénicos. Se han distinguido varias fases en la formación de los biofilms; él depositó de proteínas, seguramente motivadas por inflamación, que se adhieren a la superficie externa de la sonda formando una fina película; sobre ella, y facilitado por ellas, se irían adhiriendo las bacterias; repetidas adhesiones bacterianas y anclajes a las superficie de la sonda facilitaría la producción de polímeros; sigue a ello el crecimiento, la multiplicación y la diseminación de los microorganismos. (Donlan 2001) (31).

Cuando estudiados estos biofilms en cortes transversales se han podido reconocer diferentes capas, cada una de ellas con singularidades específicas; la más interna, la que está adherida a la sonda, es conocida como capa de enganche; sigue a continuación una capa formada por bacterias unidas de manera compacta y conocida como capa basal; finalmente, en la superficie, se reconocen numerosas bacterias flotantes, conocidas como bacterias planctónicas que constituye la capa superficial. Hay numerosos factores que pueden explicar la enorme resistencia de estos biofilms a la acción de los agentes antimicrobianos. Por un lado, las proteínas de protección y compactación restringen el acceso y difusión de los antimicrobianos. Por otro lado, no todas las bacterias que conforman el biofilms son iguales o se multiplican con igual rapidez; las bacterias más superficiales, las planctónicas, son más sensibles y fenotipicamente distintas a las localizadas en profundidad; a su vez, éstas bacterias pueden comunicarse con el exterior, recibir información, comunicarse entre ellas y transferir información genética y plásmidos que incremente sus resistencias. Se ha demostrado que las bacterias del biofilms pueden sobrevivir a concentraciones antimicrobianas 1000 y 1500 veces más altas que las concentraciones necesarias para eliminar las bacterias planctónicas de la misma especie (32).

Asumida pues la trascendencia patogénica de los biofilms en las infecciones urinarias motivadas 
por la sonda permanente, ha sido preciso indagar qué biomateriales son más resistente a está acción bacteriana o la producción de modificaciones en su superficie y contenido, que facilite la defensa e integridad del catéter durante el mayor tiempo posible. En este sentido se han realizado investigaciones con muy diversas estrategias tales como; modificar la capacidad adhesiva de las superficie; recubrir la sonda con metales pesados; general superficies antiadhesivas; incorporar en la superficie y luz del catéter antimicrobianos o antisépticos (34-41). Hemos tenido varios perros durante periodos superiores a los 6 meses con un tubo de polivinilo en el riñón (nefrostomía subcutánea) que han tolerado la situación de manera sorprendente sin depósitos cálcareos o infecciones durante el período de observación (Vela Navarrete 2000) (42).

\section{Infección urinaria de la sonda permanente: estrategias preventivas y terapéuticas}

Progresivas investigaciones en estos últimos 30 años han convertido "el caso contra el catéter" en su justa trascendencia clínica, es decir, en un equilibrio en el que los beneficios conseguidos con su uso superen a los riesgos inherentes a su aplicación. Uno de los factores fundamentales en la consecución de estos objetivos ha sido la investigación realizada para detectar los factores de riesgo, su divulgación, y la formación de personal implicado en el cuidado de sonda y catéteres. En esta estrategia ha tenido una notable importancia el trabajo urologico como corresponde a nuestro compromiso por ser los que con más frecuencia utilizamos este tipo de drenaje. La observación clínica ha permitido orientar las investigaciones para que dieran resultados prácticos a corto plazo. Ciertamente, en la actualidad los riesgos sépticos inherentes a sondas y tubos de drenaje urinario motivan menos inquietud que hace años, sin que por ello se ceda en la cautela de sus cuidados

El cuidado de la sonda permanente vesical en los ambientes no quirúrgicos, en los que no existen lesiones quirúrgicas vesicales, ni los pacientes son atendidos por expertos, debe basarse en la instrucción y formación del personal que atiende a estos pacientes. Confirmado que los sistemas de drenaje cerrado consiguen retardar la bacteriuria, estos sistemas deben ser obligatoriamente utilizados en todas aquellas circunstancias en que sea posible. Es también extremadamente importante el cuidado, con lavados y aplicaciones de antisépticos, del punto de salida de la sonda vesical en el meato. Con estas dos iniciativas se retrasa tanto la contaminación intraluminal como la que se produce por vía periuretral. La sonda uretral debe evitarse siempre que no sea estrictamente necesaria y cuando las circunstancias y comorbilidad del paciente no haga aconsejable su uso deben buscarse alternativas, como el cateterismo intermitente, los colectores externos y el drenaje suprapúbico mediante cistostomia. En cualquier caso la sonda vesical debe retirarse tan pronto como sea posible. La oportunidad de lavado vesical mediante sonda de tres vías, con o sin antisépticos apropiadamente diluidos, como clorhexidina, es otra alternativa que debe explorarse en casos seleccionados.

Los momentos de mayor riesgo séptico en pacientes con sonda permanente son aquellos en que se retira la sonda, o se cambia la sonda, o la sonda es manipulada por cualquier otro motivo. La retirada de la sonda permanente permite, a veces después de semanas de drenaje, la coincidencia de cambios de volumen y presión intravesical con decúbitos producidos por la misma sonda, facilitando el paso de bacterias al torrente circulatorio y provocando episodios sépticos graves. Estos episodios son mucho más comunes en pacientes operados, tanto por cirugía abierta como endoscópica, en los que la brecha quirúrgica producida en el urotelio, aún no cicatrizado, facilita aún más el paso de bacterias al torrente circulatorio. Es esta la circunstancia clínica que ha sido conocida en la literatura urológica con el nombre de fiebre de la retirada de la sonda (Vela Navarrete y Ales 1982) (13).

Tras la aplicación de muy variadas estrategias para el control de la misma ha podido demostrarse que el mejor procedimiento para su control consiste en la utilización de un antimicrobiano inmediatamente antes de la retirada de la sonda. La elección del antimicrobiano y su momento de aplicación depende de la farmacodinámica del mismo y de la población bacteriana frecuentemente detectada entre los pacientes con sonda. En nuestra experiencia personal desde que se aplica éste procedimiento preventivo ha sido excepcional observar episodios febriles al retirar la sonda vesical en los pacientes quirúrgicos. Esta estrategia que hemos llamado "principio de Burke" (Vela Navarrete y Alés Reinlein 1982) (13) enlaza directamente con la que corresponde al uso profiláctico de antimicrobianos en cirugía y se rige por los mismos principios. En ocasiones, cuando el tiempo de permanencia de la sonda es reducido, después de una manipulación endoscópica, exploradora o quirúrgica, una sola dosis de antimicrobianos puede cubrir ambos objetivos. Estos procedimientos preventivos son aun más necesarios, e inexcusables, cuando las sondas de drenaje permanente están en el aparato urinario superior; ninguna manipulación o cambio de sonda de nefrostomia debe hacerse sin tomar éstas precauciones. 
Frente a estas actuaciones que se han mostrado útiles en su objetivo preventivos y terapéuticos, las investigaciones de los últimos años ha podido confirmar que el uso indiscriminado de antimicrobianos, especialmente antimicrobianos de amplio espectro, no consiguen prevenir la bacteriuria de la sonda; por el contrario, promueven la sustitución y selección por bacterias más resistentes. El margen de beneficio de esta actuación es muy negativo. La bacteriuria del catéter puede reducirse, durante su permanencia, e incluso evitarse, aumentando la diuresis, acidificando la orina o usando antisépticos urinarios específicos, de muy reducido espectro como Furantoina.

La rapidez y gravedad de la formación de biofilmes está primariamente relacionada con el tipo de bacteria que produce la infección de la sonda permanente. Las bacterias ureolíticas suelen ser las que con más frecuencia motivan este proceso y no sólo en sondas de drenaje externo, a cualquier nivel del aparato urinario, sino también en los catéteres y stent intraluminales. Cuando sospechado el riesgo, el enfermo debe ser vigilado con el mayor rigor. Al menos una muestra de orina diaria debe ser analizada determinando el $\mathrm{pH}$ e investigando sedimento urinario. Un pH alcalino en orinas turbias y de olor amoniacal definitivamente justifica un cultivo de orina con indicaciones precisas para el Departamento de Microbiología advirtiendo sobre la presencia de bacterias ureolíticas. El sedimento urinario puede ser orientativo ya que Proteous es visible en orina centrifugada y esta frecuentemente asociado a cristales fosfatoamónico magnésico (Cifuentes 1974) (41).

Por el contrario, Corynebacterium Urealiticum es difícilmente reconocible en el sedimento, un argumento para advertir al departamento de microbiología sobre su posible existencia. La sospecha de bacterias ureolíticas debe imponer la acción inmediata de medidas preventivas, entre las que es fundamental el uso temprano o inmediato de antimicrobianos. Más aún, cuando la sonda permanente drena órganos debilitados por enfermedades sistémicas o procedimientos locales que alteren los mecanismos defensivos de la mucosa (cistitis radica, tumores vesicales), el uso de antimicrobianos debe ya iniciarse con carácter preventivo en el momento de colocar la sonda.

Para pacientes en los que se espera una larga permanencia de la sonda, con cambios pautados cada tres o cuatro semanas, se han diseñado sondas en las que se ha incorporado algunas modificaciones preventivas de los biofilmes, recubrimiento con metales pesados o con antimicrobianos o antisépticos (3741). La composición de estas sondas que tenemos en el mercado para larga permanencia, todas mode- lo de Foley, son de latex o de silicona compacta, o sólo recubiertas de silicona, y no se ha conseguido establecer diferencias significativas en cuanto a su propensión a formar biofilmes.

Reconocida la existencia de una infección urinaria por bacterias ureoliticas debe procederse al tratamiento de la misma, evitando daños mayores como cistitis incrustantes. Se considerará la oportunidad del cambio inmediato de la sonda vesical al mismo tiempo que se instaura el tratamiento antimicrobiano de elección, por vía oral o sistémica. Los aminoglucosidos continúan siendo muy eficaces en este objetivo y las quinolonas han aumentado de manera considerable sus resistencias en nuestro ambiente. Para el Corynebacterium Urealiticum ha podido demostrarse en nuestro laboratorio una alta sensibilidad a los glicosídicos con una sensibilidad muy irregular a las quinolonas y reducida a los beta lactamicos (Soriano 1991) (25). La coincidencia de una cistitis incrustada obliga a medidas más agresivas, tanto médicas como quirúrgicas; acidificación de la orina; instilaciones; y delegaciones vesicales con ácido cítrico o con las soluciones de Subí, Tomas, junto con la extracción endoscópica de la mucosa necrosada e incrustada.

La acción tardía de éstas medidas ha motivado en nuestra experiencia la necesidad, en dos ocasiones, de practicar una derivación urinaria ante la imposibilidad de resolver el problema con las medidas señaladas. La simple derivación urinaria ante la ausencia del soporte patogénico, la urea, paraliza el mecanismo infectivo incrustante y hace innecesaria la cistectomia.

\section{CONCLUSIÓN}

Revisamos nuestra experiencia, investigaciones, resultados y complicaciones con el uso de la sonda permanente desde nuestra primera publicación en 1969. Comparamos estas observaciones y resultados con las publicaciones que encontradas en la literatura mundial, constatando un progreso extraordinario en el reconocimiento de los mecanismos patogénicos, estrategias preventivas y terapéuticas.

Señalamos, finalmente, la trascendencia y precocidad de algunas de nuestras observaciones, varias de ellas de carácter internacional y fundamentalmente debidas al esfuerzo conjunto y mantenido de urólogos y microbiólogos. Muchas de nuestras observaciones han contribuido a reducir lo problemas sépticos comunes en los pacientes con sonda permanente, algunos de ellos de extrema gravedad. 


\section{BIBLIOGRAFÍA Y LECTURAS} RECOMENDADAS ( ${ }^{*}$ lectura de interés $y$ ** lectura fundamental)

*1. KASS, E.H.; SCHNEIDERMAN, L.J.: "Entry of bacteria into the urinary tracts of patients with indwelling catheters". New Engl. J. Med., 256: 556, 1957.

*2. BEESON, P.B.: "The case against the catheter". Amer. J. Med., 24: 1, 1958.

3. ANSELL, J.: "Some observations on catheter care". J. Chronic. Dis., 15: 675, 1962.

4. ELLIK, M.: "The care and management of indwelling kidney, bladder and urethral catheters". Office Urology R.D. Turner, Ed. It., 1963.

*5. VELA NAVARRETE, R.: "El cateterismo uretral. Cuidado y complicaciones de la sonda permanente". Rev. Clin. Esp., 113: 35, 1969.

*6. GARIBALDI, R.A.; BURKE, J.P.; DICKMAN, M.L., y cols.: "Factors predisposing to bacteriuria during indwelling urethral catheterization". J. Med., 291: 215, 1974.

**7. KUNIN, C.M.: "Detection, prevention and management of urinary tract infections". Lea \& Febiger, 1972.

8. LINDAN, R.: "El catéter uretral como fuente de sepsis urinaria". Infección del aparato urinario. Salvat Edit., 1974.

9. SEDOR, J.; MULHOLLAND, S.G.: "Hospitalacquired urinary tract infections associated with the indwelling catheter". Urol. Clin. of North Am., 26: 821, 1999.

*10. WARREN, J.; BAKKE,A.; DESGRANCHAMPS, F. y cols.: "Catheteassociated bacteriuria and the role of biomaterial in prevention". Naber KG, Pechere JC, Kumazawa J, Khoury S, Gerberding IL, Schaeffer AJ, eds. Nosocomial and health care associated infections in urology. Plymouth: Health Publications Ltd, 2001, pp. 153-176, March 2006.

11. VELA NAVARRETE, R.: "Preventive aspects vesical catéter and temporary supravesical catéter and temporary supravesical catetherization". Antibiotics Chemother, 21: 73, 1976.

*12. BULTITUDE, M.I.; EYKYN, S.: "The relationship between the urethral flora and urinary infection in the catheterised male". Brit. J. Urol., 45: 678, 1973.

**13. VELA NAVARRETE, R.; ALÉS REINLEIN, J.M.: "Infección urinaria de alto riesgo". Salvat, Barcelona, 1982.

14. ALTEMEIER, W.A.; McDONOUGH, J.J.; FULLEN, W.D.: "Third day surgical fever". Arch. Surg., 103: 158, 1971.

15. ALEX. J.M.; VELA NAVARRETE, R.: "Infección del aparato urinario". Salvat, Barcelona, 1974.

16. MILLER, A.; LINTON, K.; GILLESPIE, W. y cols.: "Catheter drainage and infection in acute retention of urine". Lancet, 1: 310, 1960.

17. GILLESPIE, W.; LENNON, G.; LINTON, K. y cols.: "Prevention of urinary infection by means of close drainage into a sterile plastic bag". Brit. Med. J., 3: 90, 1967.

*18. BUTLER, H.K.; KUNIN, C.M.: "Evaluation of specific systemic antimicrobial therapy in patients while on closed catheter drainage". J. Urol., 100: 567, 1968.

*19. THORNTON, G.; ANDRIOLE, V.: "Bacteriuria during catéter drainage. II Effect of a closed sterile drainage". JAMA., 214: 339, 1970.

20. MEYERS, M.S.; SCHROEDER, B.C.; MARTIN,C.M.: "Controlled trial of nitrofurazone and neomycin-polymyxin as constant bladder rinses for prevention of postindwelling catheterization bacteriuria". Antimicrobial Agents and Chemotherapy, 571, 1965.

21. MARTIN, C.M.; BOOKRAJIAN, E.N.: "Bacteriuria: Prevention after indwelling urinary catheterization. A controlled study". Arch. Inter. Med., 110, 703, 1962.

*22. PETERSDORF, R.G.; CURTIN, J.A.; HOEPRICH, P.D. y cols.: "A study of antibiotic prophylaxis in unconscious patients". New Engl. J. Med., 257: 1002, 1957.

23. VELA NAVARRETE, R.; ALÉS REINLEIN, J.M.: "La bacteriuria de la sonda permanente. Respuesta al tratamiento con trimetropim-sulfametoxazol (Septrim)". Rev. Clin. Esp., 120: 144, 1971.

24. SORIANO, F.; PONTE, C.; SANTAMARÍA, M. y cols.: "In vitro and in vivo study stone formation by Corynebacterium D2 (Corynebacterium urealyticum)". J. Clin. Microbiol., 23: 691, 1986.

25. SORIANO, F.; RODRÍGUEZ-TUDELA, J.L.; CASTILLA, C. y cols.: "Treatment of encrusted cistitis caused by Corynebacterium group D2 with norfloxacin, ciprofloxacin and teicoplanin in an experimental model in rats". Antimicrobial Agents and Chemotherapy, 35: 2587, 1991.

*26. SORIANO, F.; AGUADO, J.M.; FERNÁNDEZ ROBLAS, R. y cols.: "Urinary tract infection cause by Corynebacterium group D1. Report of 82 cases and review". Rev. Infect. Dis., 12: 1019, 1990.

*27. VELA NAVARRETE, R.: “Corynebacterium urealyticum o la historia de un descubrimiento anunciado". Actas Urol. Esp., 20: 201, 1996.

28. REID, G.: "Biofilms in infectious diseases and on medical devices". Int. J. Antimicrob. Agents, 11: 223, 1999.

29. HABASH, M.; REID, G.: "Microbial biofilms: their development and significance for medical device-related infections”. J. Clin. Pharmacol., 39: 887, 1999. 
30. CHOONG, S.; WHITFIELD, H.: "Biofilms and their role in infections in urology". BJU Int., 86: 935, 2000.

*31. DONLAN, R.M.: "Biofilm formation: a clinically relevant microbiological process". Clin. Infect. Dis., 33: 1387, 2001.

32. GOTO, T.; NAKAME, Y.; NISHIDA, M. y cols.: "In vitro bactericidal activities of beta-lactamases, amikacin and fluoroquinolones against Pseudomonas aeruginosa biofilm in artificial urine". Urology, 53: 1058, 1999.

*33. MORRIS, N.S.; STICKLER, D.J.; WINTERS, C.: "Which indwelling urethral catheters resist encrustation by Proteus mirabilis biofilms?". Br. J. Urol., 80: 58, 1997.

34. SOFER, M.; DENSTEDT, J.D.: "Encrustation of biomaterials in the urinary tract". Curr. Opin. Urol., 10: 563, 2000.

35. STICKLER, D.J.: "Biomaterials to prevent nosocomial infections: is silver the gold standard?". Curr. Opin. Infect. Dis., 13: 389, 2000.

36. JOHNSON, J.R.; DELAVARI, P.; AZAR, M.: "Activities of a nitro-furazone-containing urinary catheter and a silver hydrogel catheter against multidrug-resistant bacteria characteristic of catheter-associated urinary tract infection". Antimi- crobial Agents Chemotherapy, 43: 2990, 1999.

37. DAROUICHE, R.O.; SMITH, J.A. Jr.; HANNA, H. y cols.: "Efficacy of antimicrobial-impregnated bladder catheters in reducing catheterassociated bacteriuria: a prospective, randomized, multicenter clinical trial”. Urol., 54: 976, 1999.

38. LIEDBERG, H.L.: "Prospective study of incidence of urinary tract infection in patients catheterized with BARD hydrogel and silver-coated catheters or Bard hydrogel-coated catheters". J. Urol., 149: 405, 1993.

39. LUNDEBERG, T.: "Prevention of catheter-associated urinary-tract infections by use of silver-impregnated catheters". Lancet, 2: 1031, 1986.

40. RUGGIERI, M.R.; HANNO, P.M.; LEVIN, R.M.: "Reduction of bacterial adherence to catheter surfaces with heparin”. J. Urol., 138: 423, 1987.

41. RIEDL, C.R.; WITKOWSKI, M.; PLAS, E. y cols.: "Heparin coating reduces encrustation of ureteral stents: a preliminary report". Int. J. Antimicrob. Agents, 19: 507, 2002.

42. VELA NAVARRETE, R.; CASTILLA, C.; SALMAN: "Tolerance to bilateral subcutaneous acces nephrostomy in dogs. J. Urol. 140:194, 1988.

*43. CIFUENTES DELATTE, L.: "El Laboratorio del Urólogo". Salvat, Barcelona, 1974. 